\title{
Study on Prevalence and Pattern of Self Medication Practices in a Rural Area of Bihar
}

\author{
Pankaj Kumar', Arvind Kumar Vimal ${ }^{2}$ \\ ${ }^{1}$ Tutor, Department of Community Medicine/ PSM, Government Medical College, Bettiah, Bihar, ${ }^{2}$ Assistant Professor, Department of Community Medicine/ PSM, \\ Government Medical College, Bettiah, Bihar.
}

\section{Abstract}

Background: Self-medication is common in most parts. It leads to adverse effects. The present study was conducted to assess the pattern of self -medication and reasons behind this practice. Subjects and Methods: The present study was community based cross-sectional in nature conducted upon 198 adults residing in the rural field practice area. Sociodemographic profile and details of self-medication were noted. Results: $63.1 \%$ of the respondents were males. $35.9 \%$ of them belonged to the age group of $30-40$ years. $32.8 \%$ were illiterate and $85.9 \%$ were Hindu. A total of 198 respondents practiced self-medication (51.2\%). Most common symptom was headache (85.9\%). Common cold (63.1\%), fever (56.1\% and gas (31.8\%) were other common complains. Paracetamol (90.0\%), pantoprazole (51\%), other NSAIDs (42.9\%) and cold tablets $(36.9 \%)$ were other medicines used commonly. $69.2 \%$ respondents said that they were practicing it for minor illnesses, $36.9 \%$ cited economic reasons while $46 \%$ said that consulting a physician needed much time and self-medication was time saving. Conclusion: Prevalence of self-medication is high. Strict drug regulations are needed.

Keywords: Cross-sectional study, Pattern, Rural area, Self-medication.

Corresponding Author: Dr Arvind Kumar Vimal, Assistant Professor, Department of PSM, Government Medical College, Bettiah, Bihar. Email: drpklal@gmail.com

Received: December 2019

Accepted: January 2020

\section{Introduction}

Self-medication has been defined by World Health Organization as 'the selection and use of medicines by individuals to treat self-recognized illnesses or symptoms. ${ }^{[1]}$ It essentially means taking medicines by people on their own without consulting a doctor. It is often based on previous experiences, advise from the chemist or by looking at the inappropriate references e.g. google, social media etc. It is one of the components of self-care and is thought to be similar to personal hygiene, exercise, dietary modifications etc. ${ }^{[2]}$

Injudicious use of medicines is associated with various risks which include side effects, non-improvement in the illness, serious reactions and even death. It is also one of the important causes of increase in antibiotic resistance. ${ }^{[2]}$

There has been increasing trend in the practices of selfmedication. It is due to increased literacy, better access to information and lack of drug regulations for the sale of medicines. Various studies have been conducted to assess the burden of this problem. ${ }^{[2-5]}$ Prevalence of selfmedication was found to be varying between $12.7 \%$ to $95 \%$ in developing countries. The prevalence of self-medication was found to be $31 \%$ and $71 \%$ in studies conducted in Nagpur and Karnataka respectively. ${ }^{[6]}$

No such study has been conducted in this area. Hence, the present study was proposed.
Aims \& Objectives

The present study was conducted to assess the prevalence and pattern of self-medication in rural area of Bettiah, Bihar.

\section{Subjects and Methods}

\section{Study setting:}

The present study was conducted at the Department of PSM, Government Medical College, Bettiah, Bihar. The institute caters to population of West Champaran and adjoining area of Nepal.

\section{Study Design:}

The present study was cross-sectional in nature conducted at the Department of PSM, Government Medical College, Bettiah.

\section{Study subjects:}

Study subjects included adults living in the area covered by rural training center of the institute.

\section{Inclusion criteria:}

The adults living in the area covered by rural training center of the institute were included in the present study.

\section{Exclusion criteria:}

Seriously ill patients and those who refused to give consent were excluded. 


\section{Sampling:}

Sample size was calculated using the formula

Sample size $=4 \mathrm{pq} / \mathrm{d}^{2}$

Kumar et al found the prevalence of self-medication in Maharashtra to be $51.75 \% .{ }^{[4]}$ Considering relative precision of $20 \%$ and design effect of 2 , the sample size was calculated to be 185 .

20 randomly selected Anganwadi centers were approached. In each center, 10 households were selected randomly. In each household, one adult person was studied. 2 persons refused to participate. Thus, a total of 198 persons were included in the present study.

\section{Data collection procedure:}

CDPO of the block was informed and consent was taken. AWCs were approached and informed about the study and their help was taken for the household survey. Pre-tested proforma was used for data collection which included questions regarding background information, details of illness and any self-medication practiced.

\section{Data analysis:}

Data was entered in Microsoft Excel and analyzed using SPSS software. Percentage, proportions and contingency tables were used for description of the data. $\mathrm{P}$ value $<0.05$ was considered as statistically significant.

\section{Ethical consideration \& permission:}

Approval from Institutional Ethics Committee was obtained. Informed consent was taken from the patients. Confidentiality of records was maintained.

\section{Results}

A total of 198 subjects were included in the present study. [Table 1] shows sociodemographic details. $63.1 \%$ of the respondents were males. $35.9 \%$ of them belonged to the age group of $30-40$ years. $32.8 \%$ were illiterate and $85.9 \%$ were Hindu. A total of 198 respondents practiced self-medication $(51.2 \%)$.

\begin{tabular}{|l|l|l|}
\hline Table 1: showing sociodemographic details $(\mathbf{n}=\mathbf{3 8 7})$ \\
\hline Sociodemographic factor & Frequency & \% \\
\hline Age (in years) & & \\
$-<20$ & 66 & 17.1 \\
$-20-30$ & 108 & 27.9 \\
$-30-40$ & 139 & 35.9 \\
$40-50$ & 46 & 11.9 \\
$->50$ & 28 & 7.2 \\
\hline Sex & & \\
-Male & 244 & 63 \\
-Female & 143 & 37 \\
\hline Education & & \\
-Illiterate & 128 & 33.1 \\
-Primary & 108 & 27.9 \\
-Secondary and above & 151 & 39 \\
\hline Religion & & \\
-Hindu & 333 & 86 \\
-Muslim & 54 & 14 \\
\hline
\end{tabular}

[Table 2] shows the common symptoms for which selfmedication was taken. Most common symptom was headache $(85.9 \%)$. Common cold $(63.1 \%)$, fever $(56.1 \%$ and gas (31.8\%) were other common complains.

Table 2: showing symptoms for which self-medication was taken $(n=198)$

\begin{tabular}{|l|l|l|}
\hline Symptom & Frequency & \% \\
\hline Headache & 170 & 85.9 \\
\hline Fever & 111 & 56.1 \\
\hline Common cold & 125 & 63.1 \\
\hline Gas & 63 & 31.8 \\
\hline Infections & 34 & 17.2 \\
\hline
\end{tabular}

*-multiple response

[Table 3] shows the drugs used. Paracetamol (90.0\%), pantoprazole $(51 \%)$, other NSAIDs $(42.9 \%)$ and cold tablets $(36.9 \%)$ were other medicines used commonly.

Table 3: showing common drugs used for self-medication $(\mathbf{n}=198)$

\begin{tabular}{|l|l|l|}
\hline Drug used & Frequency & \% \\
\hline Paracetamol & 180 & 90.9 \\
\hline Other NSAIDs & 85 & 42.9 \\
\hline Pantoprazole & 101 & 51 \\
\hline Cold tablets & 73 & 36.9 \\
\hline Antibiotics & 59 & 29.8 \\
\hline Herbal medicines & 44 & 22.2 \\
\hline *-multiple response
\end{tabular}

[Table 4] shows the reasons cited for use of self-medication. $69.2 \%$ respondents said that they were practicing it for minor illnesses, $36.9 \%$ cited economic reasons while $46 \%$ said that consulting a physician needed much time and selfmedication was time saving.

Table 4: showing reasons for self-medication $(n=198)$

\begin{tabular}{|l|l|l|}
\hline Reason & Frequency & \% \\
\hline Minor illness & 137 & 69.2 \\
\hline Economic & 73 & 36.9 \\
\hline Lack of time & 91 & 46 \\
\hline Convenient & 50 & 25.3 \\
\hline
\end{tabular}

*-multiple response

\section{Discussion}

The present study included 198 adults residing in the field practice area of rural training center. $63.1 \%$ of the respondents were males. $35.9 \%$ of them belonged to the age group of $30-40$ years. $32.8 \%$ were illiterate and $85.9 \%$ were Hindu. Chari et al found that $46.5 \%$ respondents were male and $54.8 \%$ belonged to the age group of $18-40$ years. ${ }^{[6]}$ Keshari et al observed that $81 \%$ were males and the most common age group was $31-45$ years $(44 \%)$. Sinha et al found that $68.9 \%$ were male \& $31.1 \%$ were females. Range of age was 18 to 64 yrs. Maximum no. of subjects were in the age group 31-40 yrs. Maximum no. of subjects 155 $(47.6 \%)$ were having education up to primary level. ${ }^{[3]}$

A total of 198 respondents practiced self-medication $(51.2 \%)$. Chari et al found that prevalence of selfmedication was $35.1 \%$. ${ }^{[6]}$

Most common symptom was headache (85.9\%). Common cold $(63.1 \%)$, fever $(56.1 \%$ and gas $(31.8 \%)$ were other common complains. Paracetamol (90.0\%), pantoprazole 
(51\%), other NSAIDs $(42.9 \%)$ and cold tablets $(36.9 \%)$ were other medicines used commonly. Chari et al observed that paracetamol was most commonly used drug for headache $86.1 \%$ (179) followed by fever $(46.2 \%)$, common cold $(15.4 \%)$ and body ache $(10.6 \%)$. Ibuprofen was also commonly used for headache $(10.1 \%)$, fever $(3.8 \%)$ and body ache (3.4\%). Diclofenac was mostly used for body ache $(5.8 \%)$. Most common conditions/symptoms for selfmedication were fever $(72.6 \%)$, pain $(64.3 \%)$ and respiratory symptoms $(57.1 \%)$, followed by infections, headache and diarrhoea, etc. as found by Keshari et al. ${ }^{[3]}$ They commented that the most commonly used drugs for self-medication were paracetamol $(56.5 \%)$, drugs for gastrointestinal problems (40.5\%), nonsteroidal antiinflammatory drugs (NSAIDs) (39.9\%) followed by cold remedies, antimicrobials, etc. Sinha et al found that body ache/joint pain was most common symptom for which almost $48 \%$ subjects sought OTC. Other symptoms were headache $(27.6 \%)$ and cough $(24.9 \%)$. Painkillers were the most common group of medicine used by $55.3 \%$ subjects. Other commonly used groups of medicine were flu/cough remedies $(46.7 \%)$ and indigestion/heart burn /acidity used by $31.3 \%$ subjects. ${ }^{[2]}$

$69.2 \%$ respondents said that they were practicing it for minor illnesses, $36.9 \%$ cited economic reasons while $46 \%$ said that consulting a physician needed much time and selfmedication was time saving. Chari et al found that $80 \%$ of the people practicing self-medication did so because they felt that the problem was minor complaint and can be handled without consulting a medical practitioner. ${ }^{[6]}$ Keshari et al found that the common reasons for selfmedication were time saving $(45.2 \%)$ followed by high cost of consultation (42.3\%), minor illness (39.9\%) followed by convenience (25.0\%). ${ }^{[3]}$ Sinha et al reported that major reason for practicing OTC drug in self-medication was high cost of consultation (41.8\%), followed by mild illness/Doctor's advice not needed (21.5\%). ${ }^{[2]}$

\section{Conclusion}

About half of the respondents practiced self-medication in the past six months. Paracetamol and pantoprazole were the common medicines used. Headache, fever and gas were the common ailments. Perceiving symptom as minor illness and lack of time were the common reasons cited. Many of nonOTC drugs were being used as self-medication which can lead to adverse effects and worsening of the condition. Patient awareness and strict implementation of drugs and cosmetics act is essential.

\section{References}

1. Chauhan R. A study of the Prevalence, Pattern, and Perception of Self Medication among Medical Students in North India. Int J Contemporary Med Res 2017;4:1970-3.

2. Sinha U, Namdev G. Knowledge Attitude And Practices Among Self Medication Users In A Rural Area Of Bhopal. Natl J Community Med 2016;7:825-8.

3. Keshari SS, Kesarwani P, Mishra M. Prevalence and Pattern of Selfmedication Practices in Rural Area of Barabanki. Community Med 2014;25:636-9.

4. Kumar CA, Revannasiddaiah N. Assessment of self-medication patterns in a rural area of south India: a questionnaire based study. Int J Community Med Public Health 2017;5:354-60.

5. Limaye D, Limaye V, Fortwengel G, Krause G. Self-medication practices in urban and rural areas of western India: a cross sectional study. Int J Community Med Public Health 2018;5:2672-85.

6. Chari HS, Kadeangadi DM, Mallapur MD. Practice Of Self Medication Among Urban Households -A Community Based Cross Sectional Study. Natl J Community Med 2015;6:226-9.

Copyright: (C) the author(s), 2020. It is an open-access article distributed under the terms of the Creative Commons Attribution License (CC BY 4.0), which permits authors to retain ownership of the copyright for their content, and allow anyone to download, reuse, reprint, modify, distribute and/or copy the content as long as the original authors and source are cited.

How to cite this article: Kumar P, Vimal AK. Study on Prevalence and Pattern of Self Medication Practices in a Rural Area of Bihar. Asian J. Med. Res. 2020;9(1):CM04-CM06.

DOI: dx.doi.org/10.47009/ajmr.2020.9.1.CM2

Source of Support: Nil, Conflict of Interest: None declared. 